\title{
Soil Water Balance and Irrigation Strategies in an Agricultural District of Southern Italy
}

\author{
Domenico Ventrella*, Enza Di Giacomo, Costanza Fiorentino, Luisa Giglio, \\ Raffaele Lopez, Francesca Guastaferro, Annamaria Castrignanò \\ CRA - Unità di Ricerca per i Sistemi Colturali degli Ambienti caldo-aridi \\ Via Celso Ulpiani 5, 70125 Bari, Italy
}

Received: 19 October 2009. Accepted: 9 December 2009.

\begin{abstract}
An efficient management of water resources is considered very important for Mediterranean regions of Italy in order to improve the economical and environmental sustainability of the agricultural activity.

The purpose of this study is to analyze the components of soil water balance in an important district included in the regions of Basilicata and Puglia and situated in the Jonical coastal area of Southern Italy and mainly cropped with horticultural crops. The study was performed by using the spatially distributed and physically based model SIMODIS in order to individuate the best irrigation management maximizing the water use efficiency and minimizing water losses by deep percolation and soil evaporation. SIMODIS was applied taking in to account the soil spatial variability and localization of cadastral units for two crops, durum wheat and water melon.

For water melon recognition in 2007 a remote sensed image, from SPOT5 satellite, at the spatial resolution of 10 $\mathrm{m}$, has been used. In 2008, a multi-temporal data set was available, from SPOT5 satellite to produce a land cover map for the classes water melon and durum wheat.

Water melon cultivation was simulated adopting different water supply managements: rainfed and four irrigation strategies based on (i) soil water availability and (ii) plant water status adopting a threshold daily stress value. For each management, several water management indicators were calculated and mapped in GIS environment. For seasonal irrigation depth, actual evapotranspiration and irrigation efficiency were also determined. The analysis allowed to individuate the areas particularly sensitive to water losses by deep percolation because of their hydraulic functions characterized by low water retention and large values of saturated hydraulic conductivity. For these areas, the irrigation based on plant water status caused very high water losses by drainage. On the contrary, the irrigation scheduled on soil base allowed to control better this component of soil water balance. SIMODIS resulted a useful tool to analyse the soil water balance at spatial scale and to support the local irrigation authority for planning the irrigation water distribution.
\end{abstract}

Key-word: distributed modelling; soil water balance; irrigation efficiency.

\section{Introduction}

In Mediterranean regions of Southern Italy, the efficient use of water resources in agriculture is extremely important in order to improve the economical and environmental sustainability of the agricultural activity in an environment characterized by high evaporative demand of atmosphere, water scarcity and increasing negative consequences of climate change. Different simulation models can be used for describing the soil water fluxes at spatial and temporal scale and characterizing the physical and bio- logical processes of the soil-plant-atmosphere agrosystem. For this purpose, many deterministic models have been constituted and proposed in order to simulate, with varying degrees of complexity, processes regarding the crop (growth, root uptake, translocation of photosynthetic assimilates, etc.), soil (infiltration, runoff, profile redistribution, deep percolation, etc.), groundwater (capillary rise, water table fluctuation, etc.) and atmosphere (evaporative processes, gas fluxes, etc. ).

Numerical models are increasingly being 
used to simulate water and solute movement in the vadose zone for a variety of applications in research and soil/water management.

While a large number of models of various complexity have been developed over the years, relatively few have been tested under field conditions. Soil water flow in physically-based models is described by Richards' equation. Application of this equation requires knowledge of the soil water retention, $\theta(h)$, and hydraulic conductivity, $K(h)$, where $h(\mathrm{~L})$ is the soil water pressure head, $\theta\left(\mathrm{L}^{3} \mathrm{~L}^{-3}\right)$ is the volumetric water content and $K\left(\mathrm{LT}^{-1}\right)$ is the hydraulic conductivity.

The spatially distributed and physically based model SIMODIS (SImulation and Management of On-Demand Irrigation Systems) (D’Urso, 2001) is a Decision Support System (DSS) based on the integration of different tools such as agrohydrological hydraulic simulation model and GIS techniques where, for each calculation unit with homogeneous climate, crop and soil conditions, in which the total area can be divided, the SWAP model (van Dam et al., 1997) is applied in distributed approach. In particular the model numerically solves the following one-dimensional Richards' water flow equation:

$$
\frac{\partial \theta}{\partial t}=\frac{\partial}{\partial z}\left[\left[k(h) \cdot\left(1+\frac{\partial h}{\partial z}\right)\right]-S(z)\right.
$$

in which $\theta$ is the soil water content, $k(h)\left(\mathrm{LT}^{-1}\right)$ is the function of hydraulic conductivity, $h$ is the soil water pressure head, $z(\mathrm{~L})$ is the vertical coordinate (positive upward), $t(\mathrm{~T})$ is the time variable and $\mathrm{S}$ is the root uptake term $\left(\mathrm{T}^{-1}\right)$.

The physically based models have rarely been applied to large areas as district or basin scale because of difficulty to have the required input data about soil, crop and land use typically affected by temporal and spatial variability. For this concern, the exploiting of remote sensing information is a useful tools for several aspects, among which the spatial distribution of crop cultivation.

The land cover maps can be produced by processing remote sensed images from IKONOS or SPOT5 satellites that give an important opportunity to map ground features, which were not detectable in the past by using medium resolution remote sensed data (LANDSAT). However, classification procedure with these images is more complex than with the medium resolution remote sensing data. It is then necessary to have a multi-temporal series of images or to use classifiers taking into account also proximal information.

Following other case studies (Minacapilli et al., 2008; Minacapilli et al., 2005; D'Urso et al., 1999), the main objective of this study, carried out at distributed scale, is to analyze the components of soil water balance through the model SIMODIS, to individuate the irrigation strategies with the highest efficiency and to localize the main vulnerabilities in an important district included in the regions of Basilicata and Puglia and situated in the Ionical coastal area of Southern Italy as regarding the cultivation of durum winter wheat (Triticum durum Desf.) and water melon (Citrullus lanatus Thunb).

\section{Materials and methods}

The agricultural district of Jonical coast is located in the Puglia and Basilicata regions and has an extension of approximately $620 \mathrm{Km}^{2}$ (Fig. 1). The area extends along the coast of Jonical Sea and toward the inside of the territory to an altitude of 60 meters including the basins of four rivers: Sinni, Agri, Cavone and Basento. With an extension of 4303 ha and 21672 ha for permanently and no- irrigated lands, respectively, the area is mainly cropped with horticultural crops, orchards and vineyards, distributed in relation to the position in the landscape: fruit and vegetable crops prevail in the alluvial deposits, cereals and olive trees predominate in the marine terraces (INEA, 2001).

The data set utilized for producing the land cover maps includes: (i) a multispectral remote sensing image used to discriminate the water melon cover class, taken by SPOT5 satellite, with the spatial resolution of $10 \mathrm{~m}$ and four bands in visible and near/medium infrared spectrum, dated July 2007, and (ii) 3 multi-temporal remote sensing images taken by SPOT5 satellite in May, June and July 2008 used in order to discriminate the water melon and cereal crops cover class.

As the fields of cereal crops have a spectral signature very similar to durum wheat, in this work the cereal crops are included in the class durum wheat. For water melon recognition of 


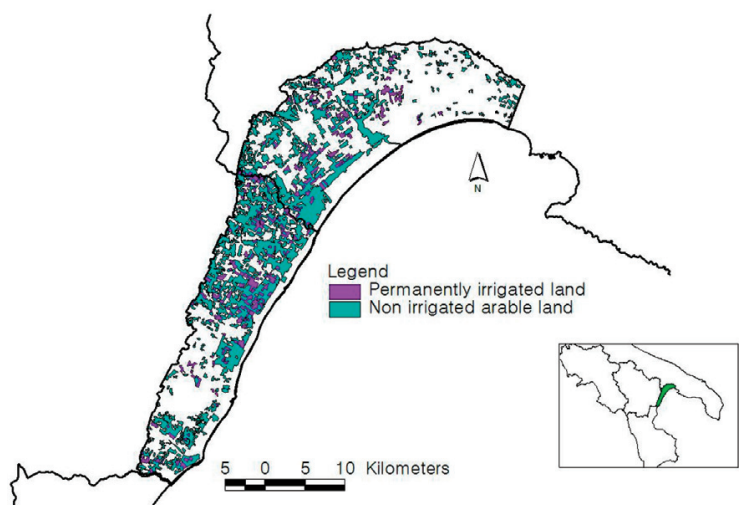

Figure 1. Land use of the study area.

2007, providing a single image, an object-oriented supervised classification technique was applied. In 2008, since it was available a multitemporal data set, a traditional Maximum Likelihood technique was applied for both water melon and durum wheat cover class (Fiorentino et al., 2010).

To investigate the multivariate spatial structure of soil data a linear model of coregionalization (Castrignanò et al., 2000) was fitted to all direct and cross-variograms of the textural components and the organic matter content of the first two pedological horizons $(0-40 \mathrm{~cm}$ for topsoil and $41-100 \mathrm{~cm}$ for subsoil), by expressing each variogram as a linear combination of the same basic structures.

Finally, all the variables were interpolated on a 500 by $500 \mathrm{~m}$-grid using the geostatistical technique of cokriging (Goovaerts, 1997). All the geostatistical analyses were performed with ISATIS software package (ISATIS, 2009).

In order to divide the study area into homogeneous soil clusters or classes, without any previous information about the existence and the number of the groups, an algorithm, based on nonparametric density estimate, was used (Scott, 1992). The approach utilises hyperspherical uniform kernels of fixed radius to estimate density. The number of clusters is a function of the radius (smoothing parameter) and generally tends to decrease as the smoothing parameter increases. However, the relationship is not strictly monotonic and several different values of the smoothing parameter generally have to be specified before choosing the optimal number of clusters. The method is not inherently hierarchical, however, it can do approximate non- parametric significance tests for the number of clusters. An approximate p-value for each cluster is computed by comparing the estimated maximum density in the cluster with the estimated maximum density on the cluster boundary. The least significant cluster is then repeatedly joined with a neighbouring cluster until all remaining clusters are significant. As the variables are not measured in comparable units, all the variables were scaled to the same mean 0 and to the same variance 1 . The clustering approach was implemented by using the MODECLUS procedure of the SAS/STAT software package (SAS, 2008, release 9.2).

In order to obtain spatially contiguous clusters the clustering algorithm was applied to the data set of the interpolated variables by cokriging and also the coordinates were included in the attribute space.

The SIMODIS model was constituted as a Decision Support System with the main goal to simulate the irrigation requirement of a irrigation district integrating different aspects as: (i) spatial and temporal variability of soil water deficit; (ii) availability and crop requirements of water resources; (iii) structural capability of irrigation networks (D'Urso, 2001). In this work the first two aspects were considered. The input data set required by SIMODIS model includes: (i) soil hydraulic parameters; (ii) vegetation parameters as upper boundary conditions; (iii) groundwater data to set the bottom boundary conditions; (iv) irrigation data concerning times and depths, fixed or automatically scheduled. The information about the soil concerns the depth and discretization of each horizon soil profile and the parameters of the functions of retention and hydraulic conductivity expressed in the parametric of Mualem-van Genuchten form (van Genuchten, 1980). In this work, the soil hydraulic parameters were determined through the pedotransfer function HYPRES (HYdraulic PRoperties of European Soils) (Wösten et al., 1998). This pedotransfer functions come from information collected in the database HYPRES containing information of 5521 soil horizons involving 20 institutions from 12 European countries. On the basis of linear regression, HYPRES estimates the hydraulic parameters of Mualem-van Genuchten equations $-\theta s$ and $\theta r$, the saturated and residual soil water content, $K s$, the saturated hydraulic con- 
ductivity and $\alpha, n$, and $l$, usually considered as fitting parameters - starting from the values of sand, silt and clay, as well as organic matter and bulk density. A qualitative variable (topsoil and subsoil), enters in the regression equations assuming values of 0 or 1 .

The crop parameters necessary for simulation concern the temporal evolution of: (i) crop coefficients $(K c)$; (ii) leaf area index ( $L A I)$; (iii) fraction cover $(F C)$. The $K c$ are used to calculate the crop evapotranspiration $\left(E T_{c}\right)$, according to the following equation (Doorenbos et al., 1977):

$$
E T_{c}=K_{c} \cdot E T_{0}
$$

where $E T_{0}$ is the reference evapotranspiration.

The leaf area index is used to divide $E T_{c}$ into potential transpiration rate, $T_{p}\left(\mathrm{LT}^{-1}\right)$ and potential soil evaporation rate $E_{p}\left(\mathrm{LT}^{-1}\right)$, according the following equations (Ritchie et al., 1972):

$$
\begin{gathered}
E_{p}=E T_{c} e^{-0.4 L A I} \\
T_{p}=E T_{c}-E_{p}
\end{gathered}
$$

The $F C$ is used in the calculation of net precipitation rate $\left(P_{n}\right)$ (Braden, 1985):

$$
P_{n}=P-a L A I\left(1-\frac{1}{1+\frac{s_{c} \cdot P}{a L A I}}\right)
$$

where $P$ is the precipitation above the canopy $\left(\mathrm{LT}^{-1}\right), a\left(\mathrm{LT}^{-1}\right)$ is an empirical parameters representing the crop saturation per unit foliage area and $s_{c}$ is the fractional vegetation cover.

Other crop variables required by SIMODIS are those related the temporal evolution of growth roots and the reduction of water uptake under condition of soil water stress $(S)$. The function $S$ is defined by the following equation:

$$
S(h)=\alpha_{w}(h) \frac{T_{p}}{\left|z_{r}\right|}
$$

where $T_{p}\left(\mathrm{LT}^{-1}\right)$ is the potential transpiration, $z_{r}$ (L) the rooting depth and $\alpha_{w}$ is a $h$ dependence reduction factor which accounts for water deficit and oxygen stress (Feddes et al., 1978).

For winter wheat the $L A I$, the $F C$, the $K c$ and root depth values are those reported by Garofalo et al. (2009). For water melon, the $L A I$ and $F C$ were measured directly during the 2007 measurement campaign of AQUATER project (Rinaldi et al., 2006), while the values of $K c$ and root growth were selected according to those suggested in the OTRIS project (Rizzo, 2000). Both for wheat and for the water melon, the parameters about the reduction of water uptake under condition of soil water stress, have been defined according to those recommended in the SWAP manual (van Dam et al., 1997).

The bottom boundary conditions are represented by free drainage at the bottom of the soil profile assuming the presence of deep watertable.

The reference evapotranspiration, required as input to the SIMODIS model, was determined using the equation of Priestly-Taylor (Priestley et al., 1972).

The daily climatic parameters were provided by the regional agency of Basilicata "Agenzia Lucana di Sviluppo e di Innovazione in Agricoltura" concerning minimum and maximum temperatures, precipitation and global radiation. In order to take in account the climate variability, we have utilized 5 data-set coming from as many meteorological stations (Ginosa Marina, Bernalda, Metaponto, Pantano Sottano and Troyli). The correspondent 5 areas were interpolated according the technique of Thiessen polygons (Fig. 2a).

For winter wheat, usually a rainfed crop, we carried out simulations without irrigation (W1). For water melon, five irrigation managements were adopted: (i) without irrigation (M1); (ii) allowed fraction of soil water deficit of $100 \%$ (M2), 50\% (M3) and 25\% (M4) with the lower limit of soil pressure head $(h)$ equal to the value below which the crop water uptake is reduced; (iii) irrigation strategy based on monitoring of plant water status with the irrigation scheduled when the ratio "actual transpiration/potential transpiration" is equal or lower than a critical fraction defined by user ( 0.98 in our case) (M5). For all the M_irrigated strategies the irrigation depth is calculated on the basis of soil water content corresponding to the filed capacity.

For each simulation run the following soil water balance indicators were considered at seasonal scale: actual transpiration $(T a, \mathrm{~mm})$, actual evaporation (Ea, $\mathrm{mm})$, deep percolation (Perc, $\mathrm{mm})$, seasonal irrigation depth $($ Irr, $\mathrm{mm})$, watering depth (Vmed, $\mathrm{mm}$ ) and seasonal number of irrigations $\left(N_{i}\right)$. 

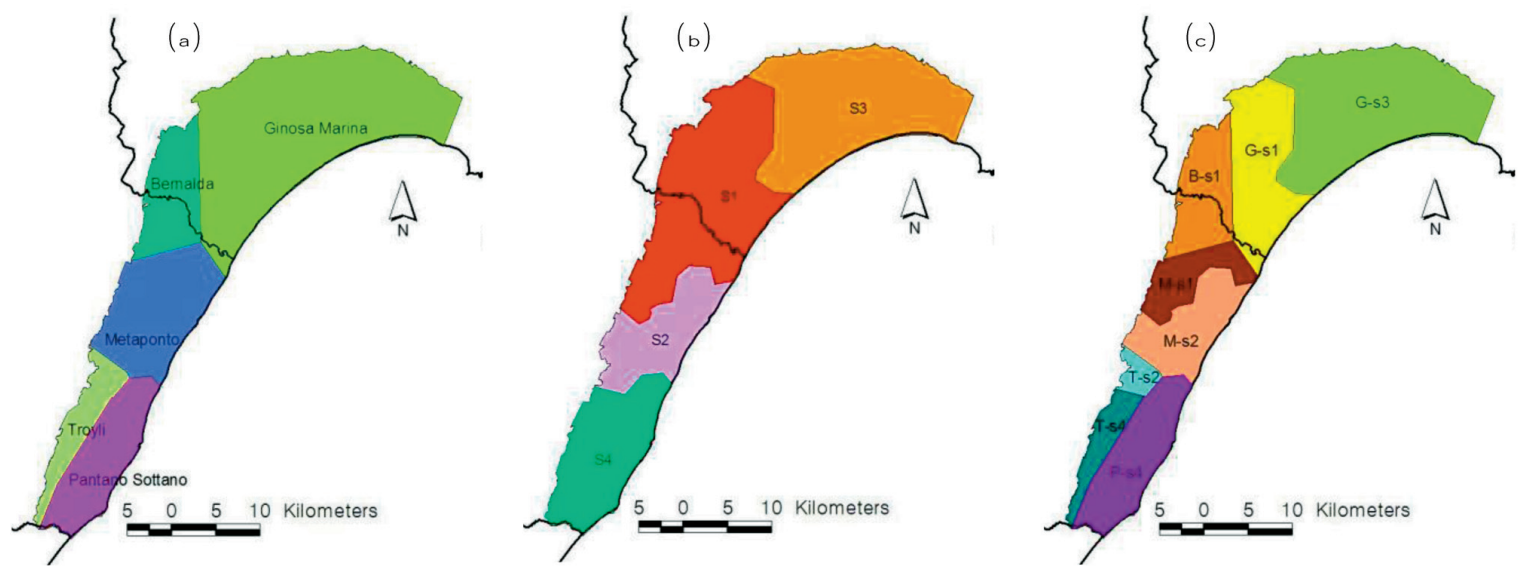

Figure 2. Map of the study area with indication of climatic areas (a) s oil clusters (b) and simulation units (c).

The irrigation efficiency $(E i)$ has been calculated by the following expression:

$$
E i=100 \cdot \frac{E T a_{i r r}-E T a_{\text {noirr }}}{\operatorname{Irr}}
$$

where $E T a_{i r r}$ and $E T a_{\text {noir }}$ are the actual evapotranspiration calculated with and without irrigation, respectively.

\section{Results}

The time evolution of main crop parameters (FC, LAI, Kc and root depth) for winter wheat and watermelon required by SIMODIS and utilized in this study are shown in Table 1.

In order to produce the soil map, taking into account the spatial dependence, an isotropic linear model of coregionalization was fitted to all variograms of the multi-variate soil data set, since no significant spatial anisotropies were disclosed. The following basic spatial structures were used for all variograms: (i) nugget effect; (ii) spherical model with range equal of $8 \mathrm{~km}$; (iii) spherical model with range of $35 \mathrm{~km}$. The cokriged maps of the soil variables (not reported) show a clear trend of finer texture from NE to SW.

After several trials, the smoothing parameter in the clustering algorithm was chosen equal to 0.52 , because it produced the split of the study area into 4 distinct classes realising the best visual accordance with the prior description of the spatial variation of the soil attributes (Fig. $2 b$ and 2c).

The clusters S1 and S3 (Tab. 2), in the Northern and Central parts of the district, respectively, are characterized by the highest percentages of sand (more than $50 \%$ ) with the first one having a significant component of clay, above all

Table 1. Crop parameters of water melon and durum wheat used by SIMODIS model.

\begin{tabular}{|c|c|c|c|c|c|c|c|c|c|}
\hline \multicolumn{6}{|c|}{ Water melon } & \multicolumn{4}{|c|}{ Durum wheat } \\
\hline Day & $\mathrm{FC}$ & LAI & $\mathrm{Kc}$ & $\begin{array}{l}\text { Root depth } \\
\quad(\mathrm{cm})\end{array}$ & Day & $\mathrm{FC}$ & LAI & $\mathrm{Kc}$ & $\begin{array}{l}\text { Root depth } \\
\quad(\mathrm{cm})\end{array}$ \\
\hline 20-Apr & 0 & 0 & 0.8 & 2 & 13-Nov & 0 & 0 & 0.4 & 2 \\
\hline 1-Jun & 0.5 & 1.3 & 0.8 & 25 & 18-Feb & 0.2 & 0.5 & 0.4 & 30 \\
\hline 8-Jun & 0.8 & 2.6 & 0.9 & 44 & 6-Mar & 0.5 & 1.3 & 0.8 & 59 \\
\hline 14-Jun & 0.9 & 3.0 & 1.0 & 60 & 23-Mar & 0.8 & 2.5 & 1.2 & 90 \\
\hline 27-Jun & 0.9 & 3.7 & 1.0 & 60 & 12-Apr & 0.9 & 3.2 & 1.2 & 90 \\
\hline 4-Jul & 0.9 & 3.1 & 1.0 & 60 & 2-May & 0.8 & 2.9 & 1.2 & 90 \\
\hline 9-Jul & 0.7 & 2.1 & 0.9 & 60 & 13-May & 0.6 & 1.4 & 0.8 & 90 \\
\hline 18-Jul & 0.1 & 0.2 & 0.7 & 60 & 25-May & 0.0 & 0.0 & 0.4 & 90 \\
\hline 7-Aug & 0 & 0 & 0.7 & 60 & 20-Jun & 0 & 0 & 0.4 & 90 \\
\hline
\end{tabular}

$\mathrm{FC}=$ soil fraction cover; LAI = leaf area index; $\mathrm{Kc}=$ crop coefficients. 
Ventrella D., Di Giacomo E., Fiorentino C., Giglio L., Lopez R., Guastaferro F., Castrignanò A.

Table 2. Texture of soils and hydraulic parameters according to Mualem-van Genuchten (1980).

\begin{tabular}{lccccclccccc}
\hline Soil & Layer & $\begin{array}{c}\text { O.M. } \\
\%\end{array}$ & $\begin{array}{c}\text { Sand } \\
\%\end{array}$ & $\begin{array}{c}\text { Silt } \\
\%\end{array}$ & $\begin{array}{c}\text { Clay } \\
\%\end{array}$ & $\begin{array}{l}\text { USDA } \\
\text { classification }\end{array}$ & $\begin{array}{c}\theta \mathrm{s} \\
\mathrm{cm}^{3} \mathrm{~cm}^{-3}\end{array}$ & $\begin{array}{c}\mathrm{Ks} \\
\mathrm{cm} \mathrm{d}^{-1}\end{array}$ & $\begin{array}{c}\alpha \\
\mathrm{cm}^{-1}\end{array}$ & $\begin{array}{c}1 \\
-\end{array}$ & $\begin{array}{c}\mathrm{n} \\
-\end{array}$ \\
\hline S1 & topsoil & 0.6 & 56.4 & 21.3 & 20.5 & Sandy clay loam & 0.388 & 51.1 & 0.058 & -2.95 & 1.21 \\
& subsoil & 0.4 & 51.7 & 22.0 & 25.6 & Sandy clay loam & 0.396 & 18.3 & 0.059 & -3.18 & 1.15 \\
S2 & topsoil & 0.8 & 33.9 & 26.8 & 32.4 & Clay loam & 0.431 & 46.8 & 0.049 & -3.76 & 1.15 \\
& subsoil & 0.6 & 21.9 & 31.8 & 38.1 & Clay loam & 0.450 & 14.1 & 0.035 & -3.34 & 1.11 \\
S3 & topsoil & 0.6 & 65.4 & 18.6 & 14.6 & Sandy loam & 0.370 & 52.8 & 0.058 & -2.04 & 1.26 \\
& subsoil & 0.5 & 59.3 & 19.7 & 19.2 & Sandy loam & 0.379 & 22.0 & 0.064 & -2.63 & 1.19 \\
S4 & topsoil & 0.9 & 19.0 & 48.1 & 27.9 & Silty clay loam & 0.434 & 21.8 & 0.027 & -3.18 & 1.17 \\
& subsoil & 0.7 & 21.3 & 43.1 & 30.7 & Clay loam & 0.435 & 17.2 & 0.030 & -3.19 & 1.13 \\
\hline
\end{tabular}

O.M. = soil organic matter; $\theta \mathrm{r}=0 ; \theta \mathrm{s}=$ saturated soil water content; $\mathrm{Ks}=$ saturated hydraulic conductivity; $\alpha, 1, \mathrm{n}=$ fitting parameters of van Genuchten equation.

in the subsoil (more than $22 \%$ ). The $K s$ of such soils are particularly high with values for the topsoil that overcame $50 \mathrm{~cm} \mathrm{~d}^{-1}$. Due to significant sandy component, the $\theta$ s are not particularly high (less than 0.39 ) contrary to the $n$ parameters (more than 1.2). Such findings indicate high rate of drainage and water profile distribution after infiltration events. In the Central and Southern part of the district the finest component of texture increases in the topsoil (32 and $28 \%$ for S2 and S4, respectively) and even more in subsoil (38 and 31\%), indicating an higher soil water retention as determined by high values of $\theta s$ (more than 0.43) and low values of $a$ and $n$ parameters (less than $0.05 \mathrm{~cm}^{-1}$ and 1.17, respectively). The $K s$, lower than 47 and $22 \mathrm{~cm}$ $\mathrm{d}^{-1}$ for $\mathrm{S} 2$ and $\mathrm{S} 4$, respectively, indicates a low infiltration rate and a sensitivity to runoff water losses.

In Figure 3 the seasonal temperatures and rainfall for the years 2007 (cycle of the watermelon) and 2007-2008 (cycle of the wheat and the watermelon) for each meteorological station considered are reported. The typical trends of a Mediterranean area are shown with the temperatures ranging from $5-10{ }^{\circ} \mathrm{C}$ (minimum and maximum) in winter to $20-35^{\circ} \mathrm{C}$ in summer and the rainfall concentrated in the period from September to March. For the second agricultural year (2008), the average seasonal precipitation was $316 \mathrm{~mm}$ with the highest value measured for Bernalda area $(413 \mathrm{~mm})$ and the lowest ones of 270 and $288 \mathrm{~mm}$ observed in Pantano and Metaponto, respectively. The same
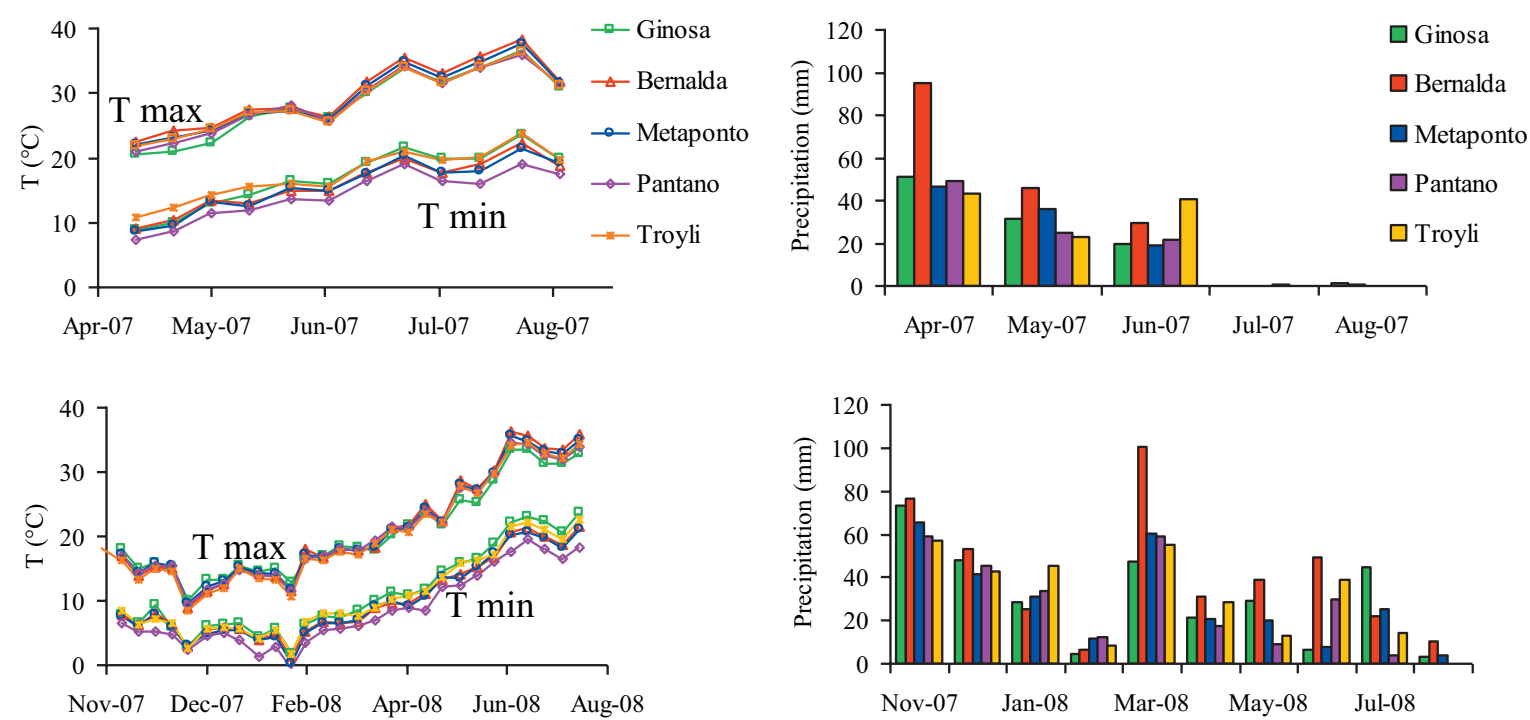

Figure 3. Climatic data of the five meteorological stations: decadal temperatures (minimum and maximum) and average monthl y values of precipitation. 
Table 3. Soil water balance components $(\mathrm{mm})$ for durum wheat simulated in the 2007/08 season.

\begin{tabular}{lccc}
\hline Map Units & Ta & Ea & Perc \\
\hline B-S1 & 154 & 77 & 103 \\
M-S1 & 189 & 55 & 56 \\
M-S2 & 184 & 55 & 69 \\
P-S4 & 162 & 72 & 72 \\
T-S2 & 186 & 74 & 62 \\
T-S4 & 187 & 74 & 71 \\
G-S1 & 187 & 69 & 55 \\
G-S3 & 186 & 69 & 56 \\
Mean & 179 & 68 & 68 \\
St. Dev. & 13 & 9 & 16 \\
\hline
\end{tabular}

$\mathrm{Ta}=$ actual transpiration $; \mathrm{Ea}=$ actual evaporation; Perc $=$ deep percolation.

rank order was obtained in the studied period of 2007 (average of $116 \mathrm{~mm}$ ) with values of 171, 96 and $101 \mathrm{~mm}$ for Bernalda, Pantano e Metaponto, respectively.

The simulation of SIMODIS were made for each season (2007 and 2007/08), crop (winter wheat and water melon) and irrigation strategy (W1 and M1-M5). A summary of results are given in Tables 3 for winter wheat and Tables 4 and 5 for water melon.

For winter wheat (Tab. 3) average actual transpiration for $2007 / 2008$ season was $180 \pm 13$ $\mathrm{mm}$, with the map units ranging between 154 and $187 \mathrm{~mm}$. The mean soil water losses by evaporation and deep percolation were $68 \mathrm{~mm}$ with a higher variability for the second one as indicated by the standard deviation values (16 $\mathrm{mm}$ vs. $9 \mathrm{~mm}$ of evaporation). The depths of drainage ranged from $55 \mathrm{~mm}$ of G-S1 to 103 $\mathrm{mm}$ for B-S1.

Observing the mean values about the culti- vation of water melon (Tab. 4), the actual transpiration increased from about $140 \mathrm{~mm}$ without irrigation (M1) to over $200 \mathrm{~mm}$, with irrigation, with peak values under M3 and M4 (about 230 $\mathrm{mm}$ ). The losses by soil evaporation ranged between 44 and $70 \mathrm{~mm}$ with a ratio "evaporation/transpiration" almost constant between 0.3 and 0.35 . At the contrary high variability characterized the losses by drainage with mean values ranging from 24 (without irrigation, M1) to $91 \mathrm{~mm}$ under M5 while the ratio "percolation/transpiration" varied from 0.1 (M3 and M4) to 0.4 (M5). The standard deviation values for each indicator indicated the variability among the 8 map units that was particularly high for percolation with variation coefficients higher than 0.3 in general due to the high or very high values that characterized the S1 and S3 soil clusters. The variability of actual transpiration and evaporation was less accentuated with mean variation coefficients of 0.1 and 0.2 , respectively.

As result of soil hydraulic characteristics and evaporative demand of atmosphere, the irrigation requirements were different among the map units. The Table 5 reports the two-year averages for water melon. Moving from M2 to M3 and M4 (decreasing the allowed soil water deficit from $100 \%$ to 50 and $25 \%$ ) the seasonal irrigation decreased from 270 to $225 \mathrm{~mm}$, the mean watering (irrigation of a single application) from $78 \mathrm{~mm}$ to 39 and $20 \mathrm{~mm}$, while the number of irrigations increased from 3.6 to 5.8 and 11.3. With the M5 strategy the highest values of seasonal irrigation depth were obtained with an average of $348 \pm 128 \mathrm{~mm}$ with $5.6 \pm 3.9$ water applications of $70 \pm 12 \mathrm{~mm}$ each.

Table 4. Two-year averages of soil water balance components $(\mathrm{mm})$ for water melon: actual transpiration (Ta), actual evaporation (Ea) and deep percolation (Perc).

\begin{tabular}{|c|c|c|c|c|c|c|c|c|c|c|c|c|c|c|c|}
\hline \multirow{2}{*}{$\begin{array}{l}\text { Map } \\
\text { units }\end{array}$} & \multicolumn{3}{|c|}{ M1 } & \multicolumn{3}{|c|}{ M2 } & \multicolumn{3}{|c|}{ M3 } & \multicolumn{3}{|c|}{ M4 } & \multicolumn{3}{|c|}{ M5 } \\
\hline & $\mathrm{Ta}$ & $\mathrm{Ea}$ & Perc & $\mathrm{Ta}$ & $\mathrm{Ea}$ & Perc & $\mathrm{Ta}$ & $\mathrm{Ea}$ & Perc & $\mathrm{Ta}$ & $\mathrm{Ea}$ & Perc & $\mathrm{Ta}$ & $\mathrm{Ea}$ & Perc \\
\hline B-s1 & 149 & 57 & 48 & 169 & 67 & 87 & 178 & 69 & 50 & 182 & 73 & 49 & 174 & 68 & 81 \\
\hline M-s1 & 145 & 33 & 20 & 233 & 62 & 71 & 252 & 67 & 20 & 253 & 76 & 20 & 233 & 63 & 65 \\
\hline M-s2 & 144 & 34 & 19 & 224 & 61 & 43 & 249 & 72 & 20 & 250 & 80 & 19 & 230 & 65 & 42 \\
\hline P-s4 & 130 & 45 & 21 & 162 & 65 & 55 & 191 & 73 & 22 & 194 & 71 & 22 & 173 & 56 & 44 \\
\hline T-s2 & 146 & 47 & 18 & 222 & 75 & 49 & 245 & 85 & 18 & 246 & 88 & 18 & 222 & 67 & 40 \\
\hline T-s4 & 153 & 47 & 20 & 206 & 71 & 51 & 242 & 87 & 22 & 246 & 88 & 21 & 216 & 66 & 39 \\
\hline G-s1 & 136 & 47 & 23 & 232 & 71 & 74 & 250 & 79 & 20 & 249 & 85 & 25 & 228 & 75 & 83 \\
\hline G-s3 & 136 & 43 & 24 & 237 & 76 & 109 & 250 & 79 & 23 & 250 & 85 & 26 & 192 & 98 & 335 \\
\hline Mean & 142 & 44 & 24 & 211 & 69 & 67 & 232 & 77 & 24 & 234 & 81 & 25 & 209 & 70 & 91 \\
\hline St. Dev. & 8 & 8 & 10 & 29 & 5 & 22 & 30 & 7 & 10 & 28 & 7 & 10 & 25 & 12 & 100 \\
\hline
\end{tabular}


Ventrella D., Di Giacomo E., Fiorentino C., Giglio L., Lopez. R., Guastaferro F., Castrignanò A.

Table 5. Two-year averages of water balance components for water melon: seasonal depth irrigations (Irr), watering depth (Vmed) and number of irrigations (Ni).

\begin{tabular}{|c|c|c|c|c|c|c|c|c|c|c|c|c|}
\hline \multirow{2}{*}{$\begin{array}{l}\text { Map } \\
\text { units }\end{array}$} & \multicolumn{3}{|c|}{ M2 } & \multicolumn{3}{|c|}{ M3 } & \multicolumn{3}{|c|}{ M4 } & \multicolumn{3}{|c|}{ M5 } \\
\hline & $\begin{array}{c}\text { Irr } \\
(\mathrm{mm})\end{array}$ & $\begin{array}{l}\text { Vmed } \\
(\mathrm{mm})\end{array}$ & $\mathrm{Ni}$ & $\begin{array}{c}\text { Irr } \\
(\mathrm{mm})\end{array}$ & $\begin{array}{c}\text { Vmed } \\
(\mathrm{mm})\end{array}$ & $\mathrm{Ni}$ & $\begin{array}{c}\text { Irr } \\
(\mathrm{mm})\end{array}$ & $\begin{array}{l}\text { Vmed } \\
(\mathrm{mm})\end{array}$ & $\mathrm{Ni}$ & $\begin{array}{c}\mathrm{Irr} \\
(\mathrm{mm})\end{array}$ & $\begin{array}{l}\text { Vmed } \\
(\mathrm{mm})\end{array}$ & $\mathrm{Ni}$ \\
\hline B-S1 & 198 & 99 & 2.0 & 150 & 36 & 3.0 & 140 & 22 & 5.5 & 241 & 80 & 3.0 \\
\hline M-S1 & 315 & 91 & 3.5 & 235 & 47 & 5.0 & 242 & 23 & 10.5 & 359 & 80 & 4.5 \\
\hline M-S2 & 249 & 71 & 3.5 & 241 & 37 & 6.5 & 243 & 18 & 13.5 & 315 & 70 & 4.5 \\
\hline P-S4 & 228 & 57 & 4.0 & 188 & 31 & 6.0 & 185 & 17 & 11.0 & 253 & 63 & 4.0 \\
\hline T-S2 & 278 & 70 & 4.0 & 244 & 35 & 7.0 & 243 & 17 & 14.0 & 308 & 69 & 4.5 \\
\hline T-S4 & 232 & 58 & 4.0 & 253 & 32 & 8.0 & 249 & 17 & 14.5 & 295 & 74 & 4.0 \\
\hline G-S1 & 290 & 83 & 3.5 & 254 & 45 & 5.5 & 246 & 22 & 11.0 & 370 & 76 & 5.0 \\
\hline G-S3 & 375 & 93 & 4.0 & 246 & 48 & 5.0 & 243 & 25 & 10.0 & 645 & 46 & 15.0 \\
\hline Mean & 271 & 78 & 3.6 & 226 & 39 & 5.8 & 224 & 20 & 11.3 & 348 & 70 & 5.6 \\
\hline St. Dev. & 57 & 16 & 0.7 & 37 & 6.7 & 1.5 & 40 & 3 & 2.9 & 128 & 12 & 3.9 \\
\hline
\end{tabular}

In Figures 4 and 5, the values of the main soil water balance components at seasonal scale (actual evapotranspiration, deep percolation and irrigation) and watering depth under water melon cultivation are reported for 2007 and 2008. The indicators were roughly characterized by the same trend with values lightly higher in 2007. The comparison between map units highlights the limited contribution of irrigation to increase ETa in the map unit B-S1 (2007 and 2008) and P-S4 (2008). Comparing M4 vs. M1 the increments of ETa are 60 and $38 \mathrm{~mm}$ (2007 and 2008, respectively) for B-S1 and $89 \mathrm{~mm}$ for P-S4 (2008), while the corresponding increments of the other map units were equal to $148 \mathrm{~mm}$ in average for the two years.

Regarding the losses by drainage the corresponding graphs highlights the high sensitivity, in order of magnitude, of M5 and M2 irrigation strategies that, for every map unit, showed the highest values of percolation depth: such a trend is particularly evident in G-S3 unit under M5. Finally, the M2 strategy involves the largest depth of watering: from 60 to $100 \mathrm{~mm}$ in both the years. At the contrary under M3 and M4 strategies the watering depth were significantly lower from 20 to $45 \mathrm{~mm}$ and much more similar to the common practice of the district.
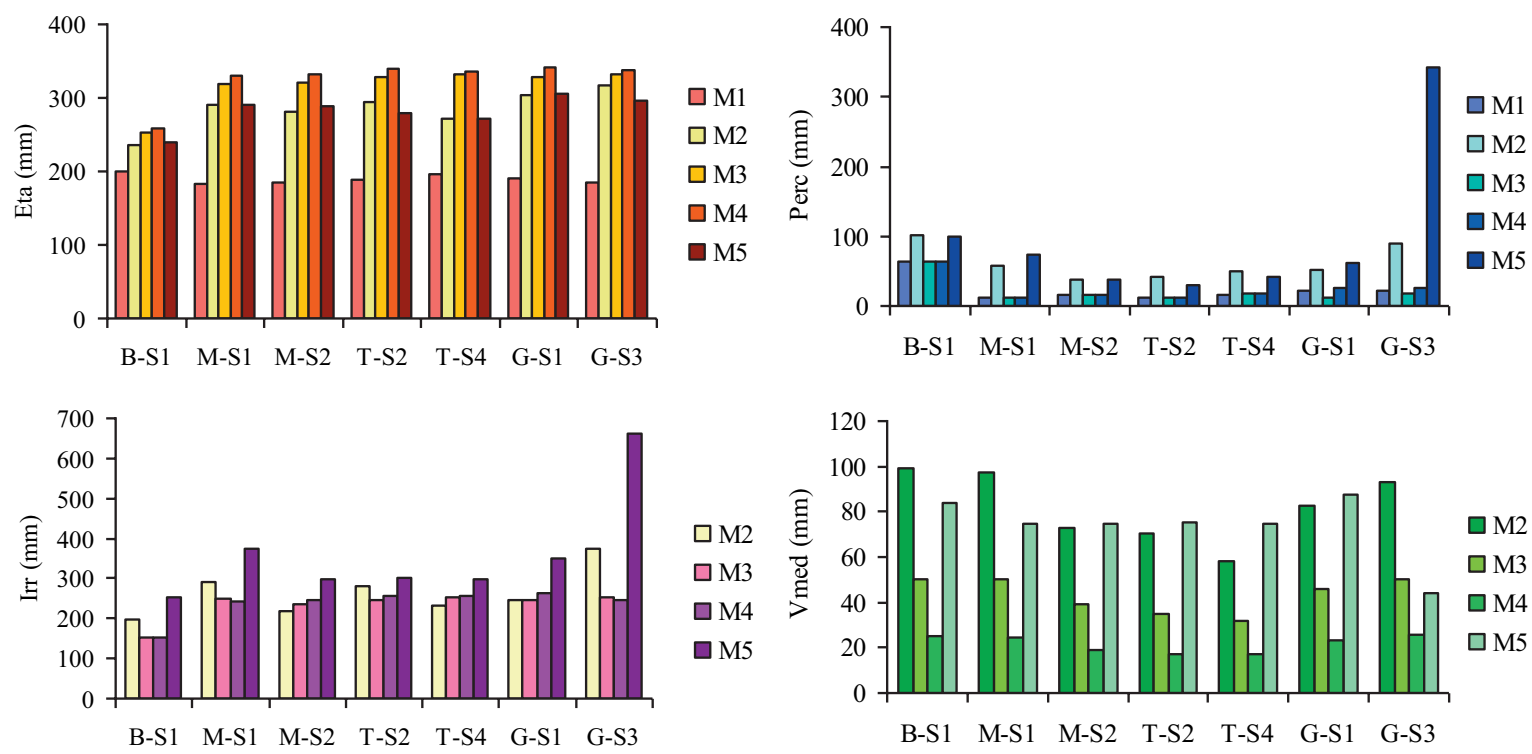

Figure 4. Results for water melon - year 2007: actual evapotranspiration (ETa), deep percolation (Perc), depth of irrigations (Irr) and mean depth of watering (Vmed). 
Table 6. Irrigation volumes $\left(\mathrm{m}^{3}\right)$ for water melon cultivation.

\begin{tabular}{lrrrrrrrrrr}
\hline Map Units & \multicolumn{9}{c}{2007} & \multicolumn{1}{c}{2008} \\
\cline { 2 - 11 } & ha & M2 & M3 & M4 & M5 & ha & M2 & M3 & M4 & M5 \\
\hline B-S1 & 240 & 474671 & 299770 & 230570 & 383522 & 99 & 194586 & 294116 & 189624 & 293791 \\
M-S1 & 152 & 442786 & 727113 & 604319 & 906341 & 111 & 377541 & 746363 & 530204 & 827767 \\
M-S2 & 98 & 213630 & 511273 & 573729 & 731117 & 225 & 628197 & 689929 & 596334 & 797713 \\
P-S4 & & & & & & 101 & 230177 & 430563 & 349399 & 468284 \\
G-S1 & 282 & 698264 & 606691 & 643018 & 919163 & 204 & 679813 & 873472 & 600616 & 888349 \\
G-S3 & 138 & 516834 & 946455 & 625055 & 1634878 & 131 & 494678 & 899107 & 572749 & 1506215 \\
\hline Sum & 910 & 2346185 & 3091302 & 2676691 & 4575021 & 871 & 2604992 & 3933550 & 2838926 & 4782119 \\
\hline
\end{tabular}

The results of land cover maps obtained from satellite information allowed to quantify the cultivation and spatial distribution in the study area. In particular, 925 ha in 2007 and 850 ha in 2008, of 62000 ha of the study area, were cropped with water melon. The area cultivated with water melon in 2007 changed in 2008 with 295 ha $(32 \%)$ retaining the same crop, 607 ha $(66 \%)$ cropping with cereal crop (particularly winter wheat) and other 23 ha (2\%) remaining as fallow or for other crops (Fiorentino et al., 2009).

Table 6 reports the crop distribution in the ing irrigation volumes determined at seasonal scale. Assuming the M3 or M4 strategy, in 2007 the irrigation requirements were homogenously distributed in areas of Ginosa Marina and
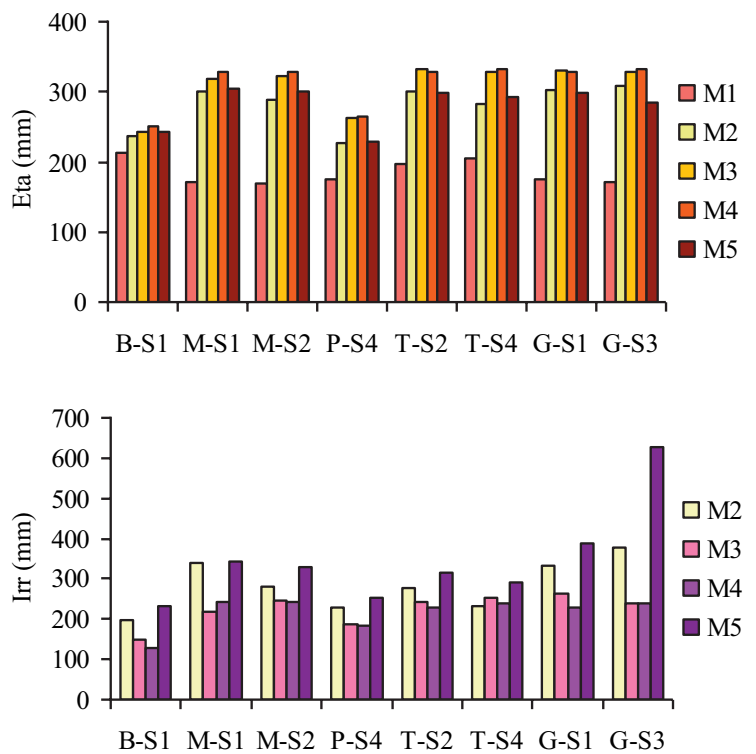
most important unit maps with the correspond-

Metaponto (50 and $40 \%$ respectively) and the remaining $10 \%$ in Bernalda area. Such spatial distribution changed in 2008 with the inclusion of Pantano area (12\%) and with the irrigation requirements of Ginosa, Metaponto and Bernalda being equal to 43,38 and $7 \%$, respectively.

In Figures 6 and 7, the maps on the spatial distribution of irrigation efficiency for each irrigation strategy and calculated with Eq. 7, is reported. In such figures the data are reported according to land use map of INEA (2001). From these figures one can see that the unit B-S1, corresponding to $\mathrm{S} 1$ soil and the climatic area of Bernalda, had always the lowest values of $\mathrm{Ei}$ in the four managements: 27 vs $45 \%$ of the other map units in 2007 and 19 vs. $46 \%$ in 2008 .

In general, the values of $E i$ increased moving from M2 to M4. Without significant differ-
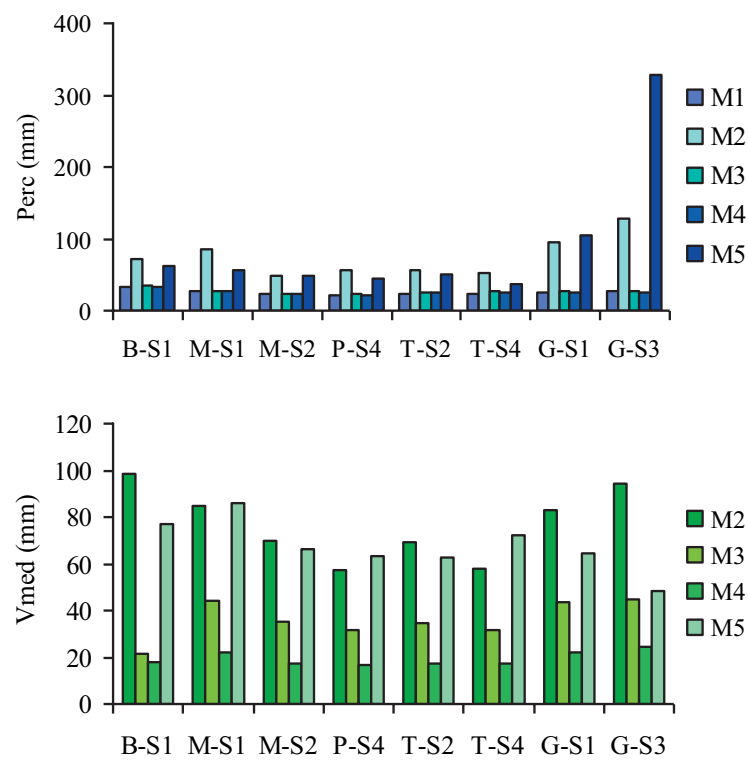

Figure 5. Results for water melon - year 2008: actual evapotranspiration (ETa), deep percolation (Perc), depth of irrigations (Irr) and mean depth of watering (Vmed). 


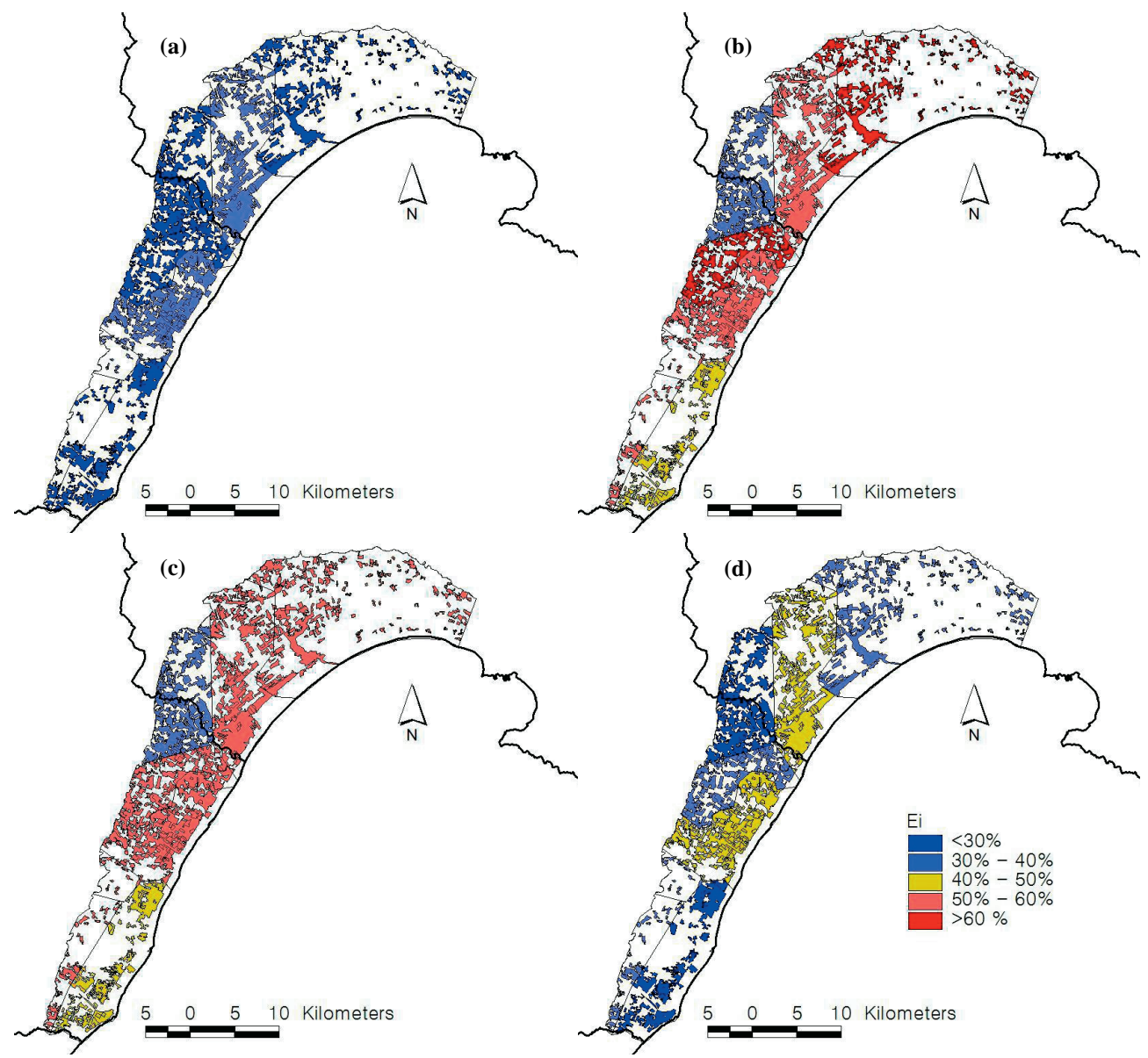

Figure 6. Irrigation efficienc y maps - year 2007: managements M2 (a), M3 (b), M4 (c) and M5 (d).

ences between 2007 and 2008, the irrigation strategies were characterized by average values equal to 34,52 and $56 \%$, for M2, M3 and M4, respectively, while the last strategy, M5, showed the lowest value and equal to $27 \%$. Such a rank order of $E i$ (M4 > M3 > M2 > M5) characterized each of the eight map unit. However, such differences are particularly pronounced in G-S3 with values of $E i$ of $18 \%$ (average of two years) for M5 vs. 62 and $67 \%$ for M4 obtained in 2007 and 2008, respectively.

\section{Conclusions}

The use of model SIMODIS allowed to estimate the principal components of soil water balance at distributed scale in an area of Southern Italy and cultivated mainly durum wheat and water melon. The approach described in this study in- volved: (1) a climatic characterization, (2) the crop cover distributions for winter wheat and water melon, obtained from processing remote sensed images (3) a delineation of homogeneous areas on the basis of information of texture and soil organic matter, (4) hydraulic characterization of the four soils applying the pedotransfer-function to estimate the hydrological parameters, and (5) the application of the physically-based SIMODIS model for the two crops in order to compare the impact on soil water balances of four different irrigation strategies.

For wheat cultivation, the soil water balance has been characterized by not significant differences among the map units with the exception of soil S1 in the Central part of the region (Bernalda) that showed the lowest value of actual transpiration and the highest one of deep percolation.

However, for water melon cultivation, this study allowed to identify the most sensitive 


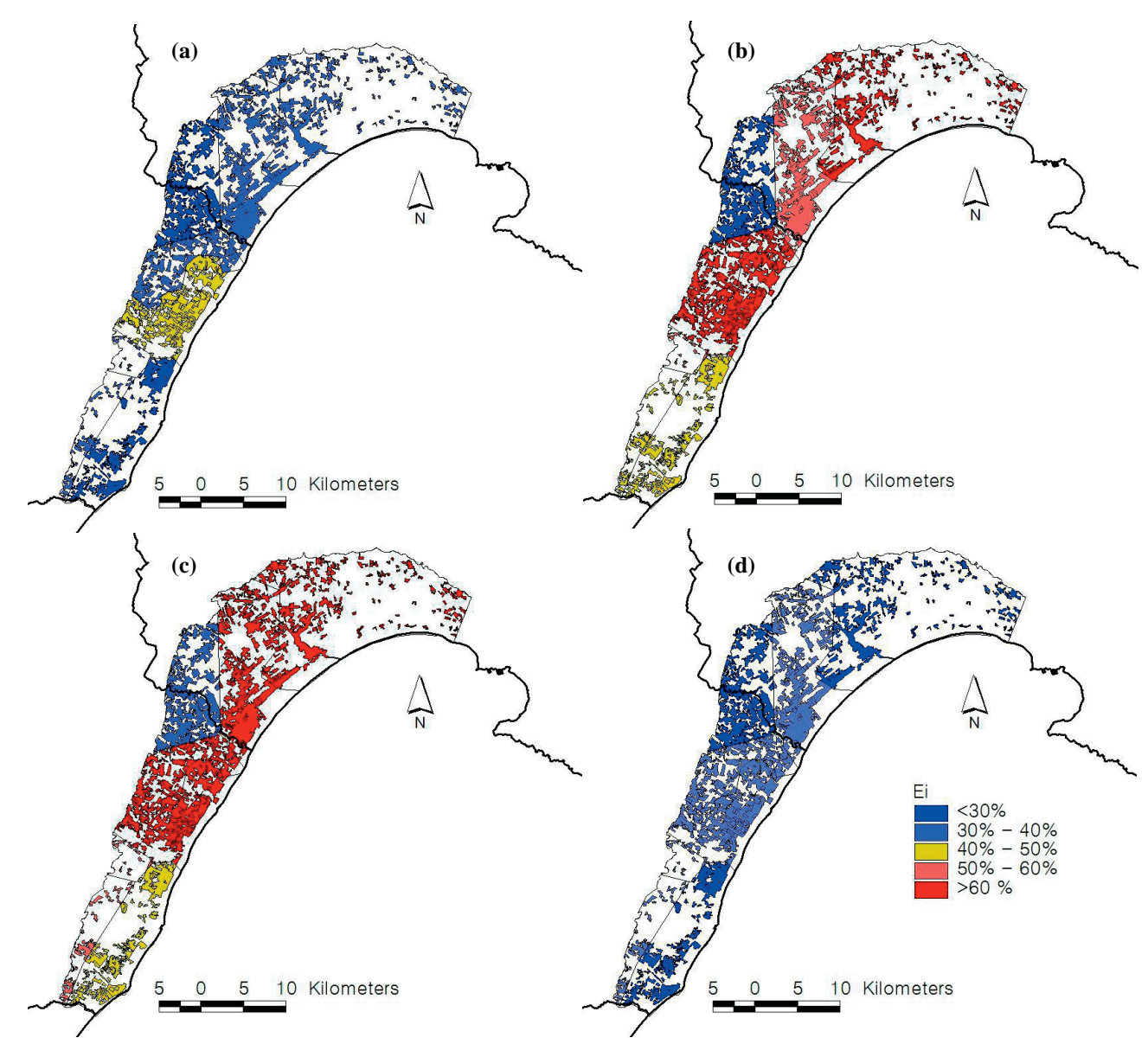

Figure 7. Irrigation efficienc y maps - year 2008: managements M2 (a), M3 (b), M4 (c) and M5 (d).

zones to water losses by deep percolation. The sandy soils, S3 in the Northern part (Ginosa) and S1 in Central part (Bernalda), characterized by low water retention and high values of hydraulic conductivity, were affected by the highest values of deep percolation and volumes of irrigation and lowest of irrigation efficiency as calculated by eq. (7).

For the irrigation strategies based on the concept of "allowable depletion of soil readily available water", the efficiency was higher when a depletable fraction of 0.25 was applied and the results obtained in term of watering depth $(20 \mathrm{~mm})$ and number of irrigation for season (about 10) were very similar to those actually adopted by the farmers of the region. With irrigation carried out when the soil water reservoir is completely depleted (M2) the losses by deep percolation tended to increase and consequently the irrigation efficiency decreased.
The irrigation strategy based on monitoring of plant water status (M5) showed lower values of efficiency compared to the other irrigation strategies or at least similar to M2, as obtained in 2007.

In conclusion, the proposed methodology based also on the application of SIMODIS, confirmed to be an useful tool to analyse the soil water balance at spatial scale and to be a functional approach usable by the local irrigation authority in order to plan the water resources distribution to irrigate profitable horticultural crops at district scale.

\section{Acknowledgment}

This work is supported by Italian Ministry of Agriculture, Food and Forestry Policies under contract n. 209/7303/05 (AQUATER Project). 


\section{References}

Braden H. 1985. Ein Energiehaushalts- und Verdunstungsmodell for Wasser und Stoffhaushaltsuntersuchungen landwirtschaftlich genutzer Einzugsgebiete. Mittelungen Deutsche Bodenkundliche Geselschaft., 42:294-299.

Castrignanò A., Giugliarini L., Risaliti R. and Martinelli N. 2000. Study of spatial relationships among some soil physico chemical properties of a field in central Italy using multivariate geostatistics. Geoderma, 97:39-60.

Doorenbos J., Pruitt W.O. 1977. Guidelines for predicting crop water requirements. FAO Irrigation and Drainage Paper 24, Rome.

D'Urso G. 2001. Simulation and Management of OnDemand Irrigation Systems: a combined agro hydrological and remote sensing approach. $\mathrm{PhD}$ thesis, Wageningen University, The Netherlands.

D’Urso G., Menenti M., Santini A. 1999. Regional application of one-dimensional water flow models for irrigation management. Agric. Water Manag., 40:291302.

Feddes R.A., Kowalik P.J., Zaradny H. 1978. Simulation of field water use and crop yield. Monographs, $\mathrm{Pu}-$ doc (Centre for Agricultural Publishing and Documentation), Wageningen, The Netherlands.

Fiorentino C., Ventrella D., Giglio L., Di Giacomo E., Lopez R. 2010. Land Use Cover Mapping of Water Melon and Cereals in Southern Italy. Italian Journal of Agronomy, 5, 2:185-192.

Garofalo P., Di Paolo E., Rinaldi M. 2009. Durum wheat (Triticum durum Desf.) in rotation with faba bean (Vicia faba var. minor L.): long-term simulation case study. Crop \& Pasture Science, 60:240-250.

Goovaerts P. 1997. Geostatistics for Natural Resources Evaluation (Oxford University Press, New York).

INEA 2001. Il progetto CASI. Guida tecnica e presentazione dei risultati. INEA, Roma.

ISATIS® 2009, release 8.0.5. Geovariances \& Ecole Des Mines De Paris: Avon Cedex, France.

Minacapilli M., Iovino M., D’Urso G. 2005. Crop and irrigation water management using high resolution remote sensing and agrohydrological models. In: D'Urso G., Osann Jochum M.A., Moreno J. (eds.): Earth Observation for Vegetation Monitoring and Water
Management. AIP Conference Proceedings, 852:99106.

Minacapilli M., Iovino M., D’Urso G. 2008. A distributed agro-hydrological model for irrigation water demand assessment. Agric. Water Manag. 95:123-132.

Priestley C.H.B. and Taylor R.J. 1972. On the assessment of surface heat flux and evaporation using large scale parameters. Mon. Weath. Rev., 100:81-92.

Rinaldi M., Castrignanò A., Mastrorilli M., Rana G., Ventrella D., Acutis M., D'Urso G., Mattia F. 2006. Decision support system to manage water resources at irrigation district level in Southern Italy using remote sensing information. An integrated project (AQUATER). In D'Urso G., Osam Jochum M.A., Moreno J. (eds.): CP852, Earth observation for vegetation monitoring and water management, AIP Conference Proceedings, 107-114.

Ritchie J.T. 1972. A model for predicting evaporation from a row crop with incomplete cover. Water Resour. Res., 8:1204-1213.

Rizzo V. 2000. Ottimizzazione dell'uso delle risorse idriche, convenzionali e non, in sistemi colturali sostenibili. L'irrigazione e la fertirrigazione delle colture erbacee ed orticole negli ordinamenti produttivi di Puglia e Basilicata. Coord. Scientifico E. Tarantino. Ecumenica Editrice.

Scott D.W. 1992. Multivariate Density Estimation: Theory, Practice, and Visualization. John Wiley \& Sons Inc., New York.

SAS Institute Inc. 2008. SAS/STAT Software Release 9.2, Cary, NC, USA.

van Dam J.C., Huygen J., Wesseling J.G., Feddes R.A., Kabat P., van Walsum P.E.V., Groenendijk P. and van Diepen C.A. 1997. Theory of SWAP version 2.0. Simulation of water flow, solute transport and plant growth in the Soil-Water-Atmosphere-Plant environment Report 71, Dpt. of Water Resources, Wageningen University, The Netherlands.

van Genuchten M.T. 1980. A closed form equation for predicting the hydraulic conductivity of unsaturated soils. Soil Sci. Soc. Am J., 44:892-898.

Wösten, J.H.M., Lilly A., Nemes A. and Le Bas C. 1998. Using existing soil data to derive hydraulic parameters for simulation models in environmental studies and in land use planning. Report 157, Winand Staring Centre, The Netherlands. 